\title{
Análise de tarefas matemáticas em uma proposta de formação continuada de professoras que ensinam matemática
}

\author{
Analysis of mathematical tasks \\ in a continuing primary teacher education scheme
}

Márcia Cristina de Costa Trindade Cyrino ${ }^{1}$. Cristina Cirino de Jesus ${ }^{2}$

\begin{abstract}
Resumo: Neste artigo, discutimos como a análise de tarefas matemáticas, em uma proposta de formação continuada, pode auxiliar professores que ensinam matemática, nos anos iniciais do Ensino Fundamental, a (re)pensar a sua prática pedagógica. Para tanto, investigamos um grupo de 14 professoras, que atuam nos anos iniciais do Ensino Fundamental em uma escola da rede municipal de ensino no Paraná, no desenvolvimento de uma proposta de formação continuada, constituída na perspectiva de um grupo de estudos, que tinha como objetivo analisar tarefas matemáticas. As reflexões e as discussões ocorridas nesse grupo de estudos nos permitiram identificar indícios de mudanças quanto: a escolha/ elaboração de tarefas, ao trabalho com os alunos, e ao enfrentamento das crenças que permeiam a prática pedagógica. O compromisso/engajamento mútuo em torno de um empreendimento articulado e um repertório compartilhado foram elementos centrais da prática dessas professoras no processo de formação continuada, e revelaram aspectos do seu desenvolvimento profissional.
\end{abstract}

Palavras-chave: Ensino de matemática. Ensino Fundamental. Formação de professores. Formação continuada.

\begin{abstract}
In this article, we discuss how the analysis of mathematical tasks, in a continuing primary teacher education scheme, can help primary teachers to reflect on their pedagogical practice. In order to achieve this purpose, we carried out a qualitative study with a group of fourteen primary teachers from an elementary school in the State of Paraná, during the development of a continuing teacher education scheme, based on the perspective of a study group, whose objective was to analyze mathematical tasks. The study group reflections and discussions enabled us to identify evidence of changes in some teachers regarding aspects such as: the choice/preparation of tasks, the work with the students and the development of pedagogical practice beliefs. The mutual commitment/engagement around a joint enterprise and a shared repertoire were central aspects of the teachers' practice during their continuing education and revealed aspects of their professional development.
\end{abstract}

Keywords: Mathematics teaching. Elementary School. Teacher education. Continuous education.

\footnotetext{
${ }^{1}$ Departamento de Matemática; Programa de Pós-graduação em Ensino de Ciências e Educação Matemática, Universidade Estadual de Londrina (UEL), Rodovia Celso Garcia Cid, Km 380, Campus universitário, CEP 86051-990, Londrina, PR, Brasil. E-mail: <marciacyrino@uel.br>

${ }^{2}$ Secretaria de Estado da Educação, Governo do Estado do Paraná, Curitiba, PR, Brasil.
} 


\section{Introdução}

O processo de ensino é constituído por vários elementos que influenciam a aprendizagem dos alunos, dentre os quais destacamos as tarefas que são propostas em sala de aula. Alguns países, na busca de promover o desenvolvimento da educação matemática, têm dado considerável atenção às tarefas matemáticas (ARBAUGH, BROWN, 2005; BISPO, RAMALHO, HENRIQUES, 2008; BRÄNDSTRÖM, 2005; CHRISTIANSEN; WALTHER, 1986; DOYLE, 1983; SHIMIZU et al., 2010; SIMON, TZUR, 2004; WATSON, SULLIVAN 2008); e pesquisadores do projeto QUASAR ${ }^{3}$, cujos principais representantes são Edward A. Silver, Mary Kay Stein, Margareth Schawan Smith, Suzanne Lane, Barbara Grover e Marjorie Henningsen. Embora as tarefas matemáticas exerçam um papel relevante na aprendizagem do aluno, no Brasil, estudos a respeito desse tema ainda são muito recentes.

As tarefas matemáticas podem ser utilizadas pelo professor como um meio para articular os conteúdos de modo a alcançar os seus objetivos de ensino (STEIN et al., 2009). A presença marcante de tarefas ${ }^{4}$ no cenário das aulas de Matemática deveria ser motivo suficiente para que os professores fossem mais criteriosos quanto a sua seleção ou elaboração. De acordo com Steele (2001, p. 42), "nenhuma outra decisão que o professor toma tem um impacto tão grande nas oportunidades de aprendizagem do aluno e na sua percepção acerca do que é a Matemática, como a seleção ou criação de tarefas". Refletir a respeito das tarefas que propõe aos alunos pode ser uma forma de o professor ficar atento aos processos de ensino e de aprendizagem e avaliar o impacto que suas decisões têm sobre estes processos.

No presente artigo apresentamos os resultados de uma pesquisa que teve como objetivo investigar como a análise de tarefas, em uma proposta de formação continuada, pode auxiliar os professores a (re)pensarem a sua prática pedagógica. Inicialmente, discutimos a importância das tarefas na prática pedagógica e sua classificação de acordo com os níveis de demanda cognitiva (proposta por pesquisadores que participaram do projeto QUASAR ${ }^{5}$ ). Em seguida, discutimos: as razões que as professoras apresentaram para justificar a escolha de tarefas; como essas tarefas são propostas em sala de aula, e indícios de mudança quanto à análise de tarefas, desencadeadas por uma proposta de formação continuada.

\footnotetext{
${ }^{3}$ Quasar Project (Quantitative Understanding: Amplifying Student Achievement and Reasoning) foi um projeto desenvolvido nos Estados Unidos com o objetivo de melhorar o ensino de matemática para estudantes que frequentavam escolas (middle schools) de comunidades economicamente desfavorecidas, com ênfase no pensamento, no raciocínio, na resolução de problemas e na comunicação de ideias matemáticas. O projeto foi fomentado pela Fundação Ford (1990-1995), dirigido por Edward A. Silver, e teve como sede o Centro de Pesquisa em Aprendizagem e Desenvolvimento da Universidade de Pittsburg.

${ }^{4}$ No decorrer do texto, utilizaremos o termo tarefas para nos referirmos a tarefas matemáticas.

${ }^{5}$ A categorização elaborada pelos pesquisadores do projeto QUASAR, para os níveis de demanda cognitiva, teve como base as categorias gerais de tarefas acadêmicas (tarefas de memorização, tarefas rotineiras ou procedimentais, tarefas de compreensão ou entendimento, e tarefas de opinião) elaboradas por Doyle (1983).
} 


\section{A importância das tarefas na prática pedagógica e os níveis de demanda cognitiva}

Alguns professores, ao planejarem suas aulas, escolhem as tarefas tendo como base os conteúdos trabalhados ou a presença dessas tarefas em livros didáticos. Neste contexto, as tarefas podem se tornar sinônimo de listas de exercícios, nas quais o trabalho dos estudantes se limita a resolvê-las de forma mecânica e, em alguns casos, tendo como ponto de partida um "exercício-modelo" explicado anteriormente pelo professor.

As tarefas assumem um papel importante nos processos de ensino e de aprendizagem, pois influenciam os alunos, na medida em que orientam sua atenção para aspectos particulares de conteúdos e especificam modos de processar a informação (DOYLE, 1983). Por isso, ao selecionar e organizar tarefas, o professor precisa ter clareza de que estas vão além dos conteúdos que devem ser mobilizados para sua realização. Elas envolvem processos cognitivos relativos à compreensão, ao estabelecimento de estratégias e procedimentos, e à validação.

Neste estudo, assumimos tarefa como uma proposição feita pelo professor em sala de aula, cujo objetivo é concentrar a atenção dos alunos em uma determinada ideia matemática (STEIN et al., 2009). Cabe ao professor "analisar as potencialidades das tarefas e adaptá-las aos seus alunos. Verificando os meios de que necessita para implementá-las na sala de aula, organizar os recursos e aprender a trabalhar com ferramentas novas, quando necessário" (PORTUGAL, 2005, p. 47).

A fim de evidenciar a relevância das tarefas e sua influência nos processos de ensino e de aprendizagem, em especial no ensino de Matemática, destacamos, a seguir, três argumentos que podem auxiliar o professor a compreender a importância de estabelecer critérios (razões) para a sua seleção. Primeiro, "as tarefas nas quais os alunos se engajam constituem, em grande medida, o domínio de oportunidades para o aluno aprender Matemática” (STEIN et al., 2009, p. 131, tradução nossa). A tarefa faz parte do dia a dia de sala de aula, e é por meio dela que o professor articula os conteúdos. Assim, o trabalho do aluno é definido pelas tarefas que ele realiza diariamente, por isso, elas podem determinar sua aprendizagem.

Um segundo argumento, presente nas pesquisas, é o de que as tarefas são instrumentos para conectar os objetivos de aprendizagem dos alunos (STEIN et al., 2009). Os professores, ao escolherem uma tarefa a ser implementada em sala de aula, precisam possuir uma intenção, um objetivo para trabalhá-la com o aluno. Ter claro os objetivos que pretende alcançar com a proposição de uma tarefa pode auxiliar o professor a criar um ambiente de sala de aula que estimule o aluno a se engajar na resolução das tarefas.

A ideia de que as tarefas determinam os raciocínios que os alunos desenvolvem ao resolvê-las (STEIN; SMITH, 1998), apresenta-se como um terceiro argumento. Diferentes tarefas constituem diferentes oportunidades de aprendizagem. Algumas têm o potencial de fomentar, nos alunos, formas complexas de pensamento, e outras não. Por isso, cada tarefa deve ser escolhida no sentido de encaminhar o aluno a desenvolver formas de raciocínio e estratégias que o permitam ultrapassar a simples memorização de fatos ou procedimentos. Segundo Stein e Smith (1998, p. 268, tradução nossa),

[...] tarefas que pedem ao aluno para realizar um procedimento memorizado em uma forma rotineira conduzem a um tipo de oportunidade para o aluno pensar; tarefas que exigem que os alunos pensem concei- 
tualmente e que estimulam os alunos a fazerem conexões conduzem a um diferente grupo de oportunidades para os alunos pensarem.

Conhecer e refletir a respeito da importância das tarefas pode permitir ao professor:

- escolher tarefas adequadas a seus objetivos de ensino;

- iniciar um processo de ensino que priorize tarefas desafiadoras ${ }^{6}$, nas quais o aluno pode estabelecer conexões com significados ou com ideias e conceitos matemáticos;

- reconhecer que as tarefas podem expressar mais do que o conteúdo;

- perceber como as tarefas influenciam o seu ensino e, consequentemente, a aprendizagem dos alunos;

- proporcionar um ambiente de aprendizagem durante as aulas de matemática; e

- perceber qual o impacto de suas ações no processo de ensino e de aprendizagem.

As tarefas podem ser analisadas sob diversas perspectivas, quais sejam: sua natureza, características, quantidade de estratégias para resolução, demandas cognitivas e outras. Neste estudo, focamos nossa análise nos níveis de demanda cognitiva das tarefas.

O nível de demanda cognitiva de uma tarefa está relacionado aos tipos de raciocínio matemático que são exigidos dos alunos para sua realização, bem como com o nível e o tipo de aprendizagem que proporciona aos alunos.

As categorias propostas pelo projeto QUASAR para classificação de tarefas (Quadro 1) de acordo com nível de demanda cognitiva envolvem: memorização, procedimentos sem conexão com significados, procedimentos com conexão com significado e fazer matemática. As duas primeiras categorias são consideradas como de baixo nível de demanda cognitiva, e as duas últimas como de elevado nível de demanda cognitiva.

Ao compreender os níveis de demanda cognitiva das tarefas e a influência que estas têm sobre a aprendizagem dos alunos, o professor pode selecionar, com mais frequência, aquelas de elevado nível. No entanto, é necessário que o professor esteja consciente de que selecionar este tipo de tarefa não é garantia de engajamento por parte do aluno em formas complexas de raciocínio. Ao escolher uma tarefa, o professor tem determinadas expectativas que podem ou não se efetivar em sala de aula, pois, no momento em que é proposta a tarefa, ganha "vida" e sofre influências das ações e interações do professor que a propõe e dos alunos que a realizam.

São vários os fatores presentes na sala de aula que podem colaborar com a manutenção ou declínio do elevado nível da demanda cognitiva de uma tarefa e fazer com que elas sofram "transformações" ao longo da aula. Ao propor a tarefa, o professor pode, consciente ou inconscientemente, alterar o nível de demanda cognitiva original da tarefa. Muitas vezes, a tarefa que é elaborada, escolhida ou adaptada do livro didático, pelo professor, não mantém o mesmo nível de demanda cognitiva quando é proposta aos alunos, e, por sua vez, quando os alunos a resolvem.

Ao lidar com tarefas de elevado nível de demanda cognitiva, torna-se essencial que o professor: não elimine os aspectos desafiadores das tarefas para os alunos; não simplifique as tarefas; não fale as respostas ou caminhos a serem seguidos pelos alunos; dê tempo suficiente

\footnotetext{
${ }^{6}$ Entendemos como tarefas desafiadoras aquelas que têm o potencial de envolver os alunos em um trabalho que desencadeia formas complexas de pensamento. 
para o aluno realizar o trabalho; considere a idade, o nível de escolaridade e o conhecimento prévio dos alunos, de modo que a tarefa constitua um verdadeiro desafio para eles (STEIN et al., 2009).

Quadro 1. Categorização dos níveis de demanda cognitiva de tarefas matemáticas

\begin{tabular}{|c|c|c|}
\hline \multirow[b]{2}{*}{ 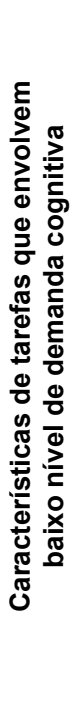 } & Memorização & $\begin{array}{l}\text { Procedimentos sem conexão } \\
\text { com significados }\end{array}$ \\
\hline & $\begin{array}{l}\text { - envolvem ou a reprodução dos fatos } \\
\text { aprendidos previamente, regras, fórmulas, ou } \\
\text { a memorização de fatos, regras, fórmulas ou } \\
\text { definições; } \\
\text { - não podem ser resolvidas usando } \\
\text { procedimentos porque estes não são exigidos } \\
\text { ou porque o tempo no qual a tarefa será } \\
\text { completada é curto para utilização de um } \\
\text { procedimento; } \\
\text { - não são ambíguas: tanto a questão que } \\
\text { envolve uma reprodução exata do material } \\
\text { visto previamente quanto o que é para } \\
\text { ser reproduzido está claro e diretamente } \\
\text { apresentado; } \\
\text { - não têm conexão alguma com os conceitos } \\
\text { ou significados que embasam os fatos, regras, } \\
\text { fórmulas ou definições que estão sendo } \\
\text { aprendidos ou reproduzidos. }\end{array}$ & $\begin{array}{l}\text { - são algorítmicas, de modo que o uso do } \\
\text { procedimento ou é especificamente pedido ou } \\
\text { está evidente a partir de uma instrução prévia, } \\
\text { experiência, ou localização da questão; } \\
\text { - requerem uma demanda cognitiva limitada para } \\
\text { uma conclusão bem-sucedida, e existe pequena } \\
\text { ambiguidade sobre o que necessita ser feito e } \\
\text { como fazê-lo; } \\
\text { - não têm conexão com conceitos ou significados } \\
\text { que estão por trás dos procedimentos usados } \\
\text { inicialmente; } \\
\text { - estão focadas na produção de respostas } \\
\text { corretas ao invés do desenvolvimento da } \\
\text { compreensão matemática; } \\
\text { - não exigem explicação, ou, quando exigem, são } \\
\text { explicações que focam, unicamente, a descrição } \\
\text { do procedimento que foi usado. }\end{array}$ \\
\hline \multirow[b]{2}{*}{ 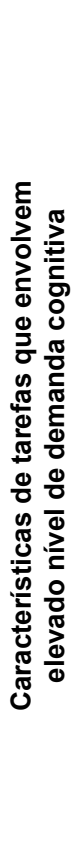 } & Procedimentos com conexão com significado & Fazer Matemática \\
\hline & $\begin{array}{l}\text { - focam a atenção dos alunos sobre o uso de } \\
\text { procedimentos, a fim de desenvolver, mais } \\
\text { profundamente, os níveis de entendimento dos } \\
\text { conceitos e ideias matemáticas; } \\
\text { - sugerem explícita ou implicitamente caminhos } \\
\text { a serem seguidos, que são procedimentos } \\
\text { amplos e gerais que têm íntima conexão com } \\
\text { as ideias conceituais; } \\
\text { - usualmente, permitem representação em } \\
\text { múltiplos caminhos, com diagramas visuais, } \\
\text { manipuladores, símbolos, e situações- } \\
\text { problemas, fazendo conexões entre múltiplas } \\
\text { representações que ajudam a desenvolver os } \\
\text { significados; } \\
\text { - exigem esforço cognitivo. Apesar de } \\
\text { procedimentos gerais poderem ser } \\
\text { seguidos, eles não podem ser seguidos } \\
\text { sem compreensão. Os alunos precisam } \\
\text { envolver-se com ideias conceituais que estão } \\
\text { por trás dos procedimentos a serem seguidos } \\
\text { para completarem a tarefa com sucesso e } \\
\text { desenvolvendo a compreensão. }\end{array}$ & $\begin{array}{l}\text { - exigem um pensamento complexo e não } \\
\text { algorítmico, e não é sugerido explicitamente, pela } \\
\text { tarefa, um caminho previsível, instruções para } \\
\text { sua execução, ou um exemplo a ser seguido, que } \\
\text { bem treinado leva à resolução da mesma; } \\
\text { - exigem que os alunos explorem e } \\
\text { compreendam a natureza dos conceitos } \\
\text { matemáticos, procedimentos, ou relações; } \\
\text { - exigem alta monitoração ou alta } \\
\text { regulamentação de seu próprio processo } \\
\text { cognitivo; } \\
\text { - exigem que os alunos mobilizem conhecimentos } \\
\text { relevantes e experiências, e façam uso } \\
\text { apropriado destes no trabalho durante a } \\
\text { resolução da tarefa; } \\
\text { - exigem que os estudantes analisem a } \\
\text { tarefa e examinem ativamente se ela pode } \\
\text { ter possibilidades limitadas de estratégias de } \\
\text { resoluções e soluções; } \\
\text { - exigem um considerável esforço cognitivo e } \\
\text { podem envolver alguns níveis de ansiedade } \\
\text { para o aluno por não ter uma lista antecipada de } \\
\text { processos exigidos para a solução. }\end{array}$ \\
\hline
\end{tabular}

Fonte: Adaptado de Stein e Smith (1998). 


\section{Contexto da investigação e procedimentos metodológicos}

Nossa pesquisa foi desenvolvida em um grupo de estudos composto por 14 professoras que ensinam Matemática nos anos iniciais do Ensino Fundamental em uma escola da rede pública do município de Apucarana - PR, localizada na periferia da cidade, que atende alunos que cursam o Ensino Fundamental ( $1^{\circ}$ ao $5^{\circ}$ ano, em período integral) e a Educação de Jovens e Adultos (EJA, oferecida somente no período noturno).

Escolhemos trabalhar com professoras que atuam neste nível de ensino por considerarmos o importante papel social que elas desempenham na formação inicial dos alunos; por serem as primeiras profissionais responsáveis pelo trabalho com as ideias matemáticas na escola; por exercerem um papel decisivo na formação matemática dos alunos; e porque tiveram um pequeno espaço reservado à matemática no seu processo de formação inicial.

As professoras envolvidas no grupo de estudos exerciam diferentes funções na escola: dez eram regentes de sala, duas eram coordenadoras pedagógicas, uma era orientadora pedagógica e, também, professora da sala de recursos ${ }^{7}$ e a outra atuava na direção da escola.

Os encontros do grupo foram semanais, com duração de uma hora, por um período de seis meses. O foco do trabalho no grupo de estudos foi conhecer e aprender a respeito dos níveis de demanda cognitiva das tarefas, com base nas categorias propostas pelo projeto QUASAR (memorização, procedimentos sem conexão, procedimentos com conexão e fazer matemática). As discussões ocorridas no grupo foram gravadas em áudio e transcritas, de modo que as "falas" das participantes pudessem ser captadas na sua forma original, mantendo a integridade dos diálogos. Após cada encontro, as participantes registravam suas impressões, dúvidas e reflexões, acerca das discussões, em um caderno de anotações que elas tinham recebido no primeiro encontro. De acordo com Phillips e Crespo (1996, p. 15, tradução nossa), "a escrita exprime o pensamento ainda mais que a fala, por exigir uma expressão mais acurada de ideias". Foram observadas, pela segunda autora deste artigo, cinco aulas de três participantes do grupo (duas aulas da professora Denise ${ }^{8}$, duas aulas da professora Cláudia e uma aula da professora Fernanda). Segundo Lüdke e André (1986, p. 26), "a observação permite que o observador chegue mais perto das perspectivas dos sujeitos". As observações permitiram perceber o modo como as professoras lidavam com as tarefas em sala de aula e possibilitaram um contato e uma interação mais direta com essas participantes. Essas aulas foram discutidas no grupo de estudos e, após o último encontro, foram realizadas entrevistas semiestruturadas ${ }^{9}$ com algumas professoras, na busca de aprofundar nossa investigação.

O grupo de estudos foi proposto e coordenado por pesquisadoras do Programa de Pósgraduação em Ensino de Ciências e Educação Matemática (PECEM), e fez parte de um projeto de formação continuada traçado pela escola junto à Secretaria Municipal de Educação em seu

\footnotetext{
${ }^{7}$ A sala de recursos é uma sala ambiente destinada aos alunos que possuem dificuldades de aprendizagem e que foram avaliados por uma psicopedagoga e por uma psicóloga. Esses alunos são matriculados nas turmas regulares e frequentam a sala de recursos de acordo com um cronograma elaborado pela professora responsável pela sala. ${ }^{8}$ Usamos nomes fictícios para preservar a identidade das professoras envolvidas.

${ }^{9}$ Entrevistamos seis das 14 professoras. Escolhemos entrevistar as professoras que mais frequentaram os encontros. As entrevistas foram realizadas individualmente e na escola, em horário combinado anteriormente com cada uma.
} 
planejamento anual. A constituição de um grupo de estudos com professores que atuam nos anos iniciais teve como um dos objetivos investigar como a análise de tarefas, em uma proposta de formação continuada, pode auxiliar os professores a (re)pensar a sua prática pedagógica.

As discussões do grupo foram organizadas em quatro momentos. No primeiro momento foram discutidas as tarefas ${ }^{10}$ trazidas pelas professoras. Elas apresentaram os motivos que nortearam a escolha dessas tarefas e como lidavam com a proposição de tarefas em sala de aula. No segundo momento, as professoras estudaram e discutiram as características de tarefas em cada nível de demanda cognitiva (Quadro 1), para realizar uma nova análise dessas tarefas, classificando-as de acordo com o nível de demanda cognitiva. Em um terceiro momento, as professoras resolveram tarefas de diferentes níveis de demanda cognitiva propostas pela coordenadora do grupo de estudos, analisaram e classificaram essas novas tarefas, e algumas professoras manifestaram o interesse de aplicá-las em sala de aula. Após essa aplicação, no quarto momento, o grupo de estudos discutiu os pontos considerados relevantes e as dificuldades enfrentadas pelas professoras em sala de aula, bem como avaliou a importância da análise de tarefas e dos níveis de demanda cognitiva.

Para construirmos as unidades de análise, utilizamos as transcrições dos encontros, as produções escritas das professoras, as entrevistas e as anotações das observações de aula, destacando os trechos relevantes para nosso estudo. Em seguida, agrupamos essas informações por encontro, por participante e por instrumento de coleta, separando as informações de modo que pudessem ser comparadas, para procurarmos pontos de enfoque (BARDIN, 1977). Para identificar o instrumento do qual fora retirada uma informação descrita na análise, utilizamos, logo após a sua descrição, o nome fictício, para manter o anonimato da participante, seguido da letra inicial do instrumento e a data em que a informação foi obtida. Assim, para os encontros do grupo, utilizou-se a letra $G$, para as produções escritas, $P$, para as observações de aulas, $O$, e, para as entrevistas, E. Por exemplo, para identificar uma informação fornecida por Cintia no $1^{\circ}$ encontro do grupo no dia 25/10/2010, após a transcrição registramos: (CINTIA, G1, $25 / 10 / 2010)$.

\section{Razões para escolha de tarefas matemáticas e como são propostas em sala de aula}

Nos primeiros encontros, discutimos as tarefas trazidas pelas professoras, na busca de identificar os argumentos que elas utilizam para justificar a escolha dessas tarefas e como essas são propostas em sala de aula (Quadro 2).

As professoras revelaram aspectos que estão presentes no ideário do professor que ensina Matemática nos anos iniciais e que precisam ser ponderados.

Ao selecionar tarefas, é necessário pensar nos conteúdos, mas isso não é suficiente. Escolher tarefas tendo em vista somente um determinado conteúdo matemático é comum a muitos professores. Esses professores, muitas vezes, utilizam um planejamento guiado por conteúdos matemáticos e as tarefas são assumidas como um meio para alcançar a aprendizagem

\footnotetext{
${ }^{10}$ As professoras entregaram as tarefas para as pesquisadoras dois dias antes do início do grupo. Optamos por recolhê-las antecipadamente para garantir que as professoras tivessem as tarefas em mãos no momento da discussão.
} 
Quadro 2. Síntese das razões apresentadas pelas professoras para escolha das tarefas e como lidavam com essas tarefas em sala de aula

\begin{tabular}{|c|c|c|}
\hline \multirow{4}{*}{ 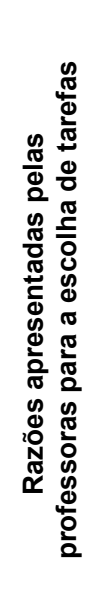 } & $\begin{array}{l}\text { As tarefas permitem } \\
\text { trabalhar os conteúdos } \\
\text { matemáticos. }\end{array}$ & $\begin{array}{l}\text { Quando vou preparar a aula, eu vejo assim, vou dar frações, então } \\
\text { pego o livro e separo os exercícios que envolvem frações, se for } \\
\text { outro conteúdo faço a mesma coisa. (FERNANDA, O3, 07/06/10) }\end{array}$ \\
\hline & $\begin{array}{l}\text { As tarefas permitem } \\
\text { verificar se o conteúdo } \\
\text { matemático foi "assimilado". }\end{array}$ & $\begin{array}{l}\text { Eu escolhi esta tarefa para verificar se os alunos sabiam } \\
\text { multiplicação, a tabuada do dois. (ANA LIVIA, G1, 04/05/10) }\end{array}$ \\
\hline & $\begin{array}{l}\text { As tarefas permitem } \\
\text { trabalhar com aspectos não } \\
\text { matemáticos. }\end{array}$ & $\begin{array}{l}\text { [...] eu quis com este problema (discutir) a questão do ler, porque } \\
\text { tem bastante pontuação; a questão ambiental, animais em extinção; } \\
\text { deveres, direitos e proibições, questão de condutas sociais... } \\
\text { (CLÁUDIA, G1,04/05/10) }\end{array}$ \\
\hline & $\begin{array}{l}\text { As tarefas permitem } \\
\text { relacionar a matemática } \\
\text { com a realidade do aluno. }\end{array}$ & $\begin{array}{l}\text { Eu gosto mesmo de trazer o problema para a realidade deles. [...] } \\
\text { sempre para a realidade da criança, ela aprende a matemática } \\
\text { para a vida. [...] Quando elas resolvem problemas da realidade, têm } \\
\text { muito mais prazer. (MARIANA, G1, 04/05/10) }\end{array}$ \\
\hline \multirow{3}{*}{ 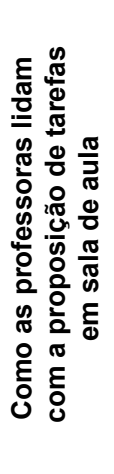 } & $\begin{array}{l}\text { Interpretam as tarefas no } \\
\text { lugar dos alunos. }\end{array}$ & $\begin{array}{l}\text { Eu dou a tarefa e vou acompanhando, eu leio para eles, vou } \\
\text { interpretando, circulo os dados, senão eles não conseguem. } \\
\text { (ISADORA, P6, 22/06/10) }\end{array}$ \\
\hline & $\begin{array}{l}\text { Questionam o aluno para } \\
\text { que ele explique como } \\
\text { pensou. }\end{array}$ & $\begin{array}{l}\text { Ao dar uma tarefa, eu vou perguntando para os alunos como } \\
\text { fizeram, porque fez aquilo, não dá para eles escreverem por que } \\
\text { são primeiro ano, mas vou perguntando oralmente. Acho isso } \\
\text { importante porque ajuda o aluno para qual faço a pergunta e } \\
\text { também os coleguinhas que às vezes não entenderam. (CÍNTIA, } \\
\text { G8,13/07/10) }\end{array}$ \\
\hline & $\begin{array}{l}\text { Valorizam a resposta } \\
\text { correta em detrimento do } \\
\text { processo. }\end{array}$ & $\begin{array}{l}\text { Ao dar uma tarefa o importante para mim é a resposta correta, se o } \\
\text { aluno acertou e pronto. (GISELE, G1, 04/05/10) }\end{array}$ \\
\hline
\end{tabular}

Fonte: elaborado pelas autoras.

desses conteúdos. No entanto, restringir a escolha da tarefa ao conteúdo a ser contemplado na sua resolução pode conduzir a uma forma limitada de trabalhá-la, pois as tarefas não determinam somente o conteúdo que os alunos aprendem, mas suas concepções de matemática, modos de pensar sobre, desenvolver, usar e dar sentido à matemática (STEIN; GROVER; HENNINGSEN, 1996).

Propor uma tarefa com o objetivo de "verificar o que foi assimilado" pode não ser muito eficiente, pois a maioria das tarefas que têm como foco a verificação é de memorização (baixo nível de demanda cognitiva). Sabemos que as tarefas de memorização têm sua importância, mas o professor tem de cuidar para que o seu processo de ensino não priorize somente este tipo de tarefa, que apenas produzem resultados em curto prazo e não indicam se o aluno compreendeu os procedimentos, as regras, os fatos matemáticos; “[...] são os níveis de engajamento cognitivo do aluno, em última instância, que determinam o que é aprendido" (STEIN et al., 2009, p. 15, tradução nossa).

É comum, ao professor que trabalha com os anos iniciais do Ensino Fundamental, escolher tarefas com a intenção de trabalhar aspectos não matemáticos que compõem seu pla- 
nejamento, por conta de serem os responsáveis por outros aspectos da formação, por outros conteúdos, não só os de matemática, e por serem incentivados a trabalhar de forma interdisciplinar. É importante que, ao trabalhar uma tarefa matemática explorando outros aspectos, o professor fique atento para não perder o foco principal da proposição daquela tarefa. $O$ fato de utilizar tarefas matemáticas para desenvolver outros conteúdos não garante a interdisciplinaridade. É essencial que o professor seja prudente e tenha clareza dos objetivos que pretende atingir com a tarefa proposta, para que, ao dar ênfase a outros aspectos, não transforme uma tarefa matemática em uma ação não matemática (STEIN et al., 2009).

As professoras que justificaram que o critério de escolha das tarefas estava relacionado ao fato de trabalharem aspectos não matemáticos foram as mesmas que disseram que as tarefas devem estar relacionadas com a realidade do aluno. O fato de o aluno "vivenciar" a situação proposta pela tarefa pode não garantir seu engajamento na resolução e na compreensão dos conceitos matemáticos envolvidos nessa tarefa. Para essas professoras, a aprendizagem só acontece no trabalho com tarefas consideradas prazerosas para o aluno.

Quanto à proposição de tarefas em sala de aula, foi possível perceber que algumas professoras "interpretam as tarefas no lugar de seus alunos", pois consideram as "suas" leituras essenciais para que o aluno as resolva. Segundo Stein et al. (2009), ao lerem e interpretarem a tarefa para os alunos, estas professoras podem eliminar os aspectos desafiadores da tarefa, modificando seu nível de demanda cognitiva original. Alguns alunos já sabem que a professora vai ler e interpretar o problema e ficam à espera das "dicas" e das propostas de resolução por ela fornecidas. Por outro lado, há professoras que, ao proporem a tarefa, elaboram questões provocativas, preservando a complexidade da tarefa, para que os alunos pensem e verbalizem o que estão pensando a respeito da tarefa, com o objetivo de "[...] promover o fazer-sentido e os níveis de compreensão” (STEIN et al., 2009, p. 15, tradução nossa).

Segundo Bispo, Ramalho e Henriques (2008), as tarefas devem promover momentos de interação e colaboração entre alunos e professores, funcionando como motores que promovem a aprendizagem e o desenvolvimento do conhecimento matemático. Deve ser uma interação em que o professor respeite a produção de seus alunos, dando-lhes o tempo e o apoio necessário para a realização da tarefa, valorizando o processo de resolução, e não somente a resposta correta. Ao privilegiar somente a resposta correta, o professor desloca a ênfase dos conceitos ou da compreensão para um produto final que nem sempre tem significado para o aluno (STEIN et al., 2009). As respostas dos alunos, corretas ou não, podem fornecer oportunidades para os professores refletirem sobre quais perguntas devem ser feitas a eles, de modo a tentarem entender o que estão pensando e, a partir daí, (re)orientarem seu trabalho.

\section{Indícios de mudanças desencadeadas por uma proposta de formação continuada}

As reflexões e as discussões ocorridas no grupo de estudos, desencadeadas pelo estudo dos níveis de demanda cognitiva de tarefas, pela análise de tarefas e dos pontos considerados relevantes na aplicação dessas tarefas em sala de aula (incluindo as dificuldades que enfrentaram), nos permitiram identificar indícios de mudanças quanto: a escolha/elaboração de tarefas, ao trabalho com os alunos e ao enfretamento das crenças que permeiam a prática pedagógica (Quadro 3). 
Quadro 3. Frases que evidenciam indícios de mudança

\begin{tabular}{|c|c|}
\hline Indícios de mudanças & Frases que evidenciam os indícios de mudança \\
\hline \multirow{2}{*}{$\begin{array}{l}\text { Quanto à escolha/ } \\
\text { elaboração de tarefas }\end{array}$} & $\begin{array}{l}\text { [...] agora ao escolher uma tarefa não me prenderei em tarefas de repetições, } \\
\text { mas em tarefas que irão exigir atenção, concentração e mexer com o cognitivo, } \\
\text { para fazer com que o aluno além de aprender, se encante e goste realmente de } \\
\text { matemática, tendo um pensamento mais abrangente trabalhando assim com } \\
\text { pensamento algébrico. (JULIANA, G19, 23/11/10) }\end{array}$ \\
\hline & $\begin{array}{l}\text { Essas reflexões têm contribuído muito para a escolha de tarefas matemáticas e } \\
\text { também em outras disciplinas. Estamos ficando mais criteriosas, não pensamos } \\
\text { só nos objetivos mas também no grau de complexidade, nos alunos, e tentamos } \\
\text { imaginar como eles irão reagir diante daquela tarefa, quais as possíveis respostas } \\
\text { que encontrarão. (CINTIA, P6, 23/06/10) }\end{array}$ \\
\hline \multirow{2}{*}{$\begin{array}{l}\text { Quanto ao trabalho } \\
\text { com alunos }\end{array}$} & $\begin{array}{l}\text { O que me surpreendeu na aplicação da tarefa de elevado nível foi que aqueles } \\
\text { alunos que são "rápidos" para fazer uma continha, um probleminha fácil, } \\
\text { apresentam dificuldades quando estão realizando tarefas de elevado nível de } \\
\text { exigência. E aqueles que eu "considerava" mais fraquinhos não tiveram tanta } \\
\text { dificuldade. Fiquei surpresa com a participação de alguns alunos. (DENISE, G8, } \\
\text { 13/07/10) }\end{array}$ \\
\hline & $\begin{array}{l}\text { Eu aprendi a valorizar o meu aluno e vi que ele é capaz. Porque eu pensava } \\
\text { assim, ah, o aluno é de escola pobre da periferia, ah, então eu vou ensinar } \\
\text { mecanicamente e se ele aprender isso está muito bom. Mas não é só isso, ele } \\
\text { pode ir além, eu não sabia o poder dessas crianças, mas quando apliquei a tarefa } \\
\text { que vocês sugeriram eu vi que estava errada e que a gente tem que ir além. } \\
\text { (MARIANA, E, 30/11/10) }\end{array}$ \\
\hline \multirow{2}{*}{$\begin{array}{l}\text { Quanto ao } \\
\text { enfrentamento } \\
\text { das crenças que } \\
\text { permeiam a prática } \\
\text { pedagógica }\end{array}$} & $\begin{array}{l}\text { Os encontros fazem com que repensemos nossa prática pedagógica, nos auxilia } \\
\text { para melhor elaborarmos as atividades propostas aos alunos, levando em conta } \\
\text { sua demanda cognitiva (baixo ou elevado). (FABIANE, P5, 08/06/10) }\end{array}$ \\
\hline & $\begin{array}{l}\text { A minha escolha de tarefas mudou, consequentemente isto vai mudar também } \\
\text { a minha prática pedagógica, porque não dá para escolher uma tarefa de nível } \\
\text { elevado e continuar agindo do mesmo jeito na sala. (FERNANDA, P12, 16/09/10) }\end{array}$ \\
\hline
\end{tabular}

Fonte: elaborado pelas autoras.

\section{Quanto à escolha/elaboração de tarefas}

Nas primeiras discussões no grupo de estudos, foi possível perceber que as professoras não tinham o hábito de "pensar" a respeito das tarefas que trabalham em suas aulas. As razões explicitadas por algumas professoras, muitas vezes, não guardavam relação com a demanda cognitiva da tarefa.

As ações desenvolvidas ao longo do grupo de estudos, nomeadamente o estudo dos níveis de demanda cognitiva de tarefas, a análise de tarefas e discussões a respeito da aplicação de tarefas em sala de aula, desafiaram as professoras a (re)pensarem o papel das tarefas e, por conseguinte, as razões para sua escolha/elaboração. As professoras passaram a levar em conta o nível de demanda cognitiva e valorizar aquelas classificadas como de elevado nível de demanda cognitiva (Quadro 4).

De acordo com algumas professoras, as tarefas com elevado nível de demanda cognitiva têm o potencial para desenvolver o raciocínio dos alunos. Elas agregaram outras razões para propor tarefas, além das que já expressavam. 
Quadro 4. Reflexões a respeito da análise de tarefas e dos níveis de demanda cognitiva

\begin{tabular}{|c|l|l|}
\hline \multirow{2}{*}{$\begin{array}{c}\text { Reflexões } \\
\text { a respeito } \\
\text { da análise } \\
\begin{array}{c}\text { de tarefas e } \\
\text { dos níveis } \\
\text { de demanda } \\
\text { cognitiva }\end{array}\end{array}$} & $\begin{array}{l}\text { A relevância de conhecer os } \\
\text { níveis de demanda cognitiva } \\
\text { de tarefas matemáticas }\end{array}$ & $\begin{array}{l}\text { Conhecer as demandas cognitivas das tarefas me } \\
\text { ajudou a não escolher as tarefas somente pelas } \\
\text { suas características superficiais. (GISELE, G6, } \\
\text { 22/06/10) }\end{array}$ \\
\cline { 2 - 3 } & $\begin{array}{l}\text { A relevância das tarefas de } \\
\text { elevado nível de demanda }\end{array}$ & $\begin{array}{l}\text { É extremamente importante trabalhar com tarefas } \\
\text { de elevado nível, pois são elas que permitirão } \\
\text { desenvolver em nossos alunos a autonomia, a } \\
\text { confiança em si, o pensar crítico, a argumentação, } \\
\text { logo a pensar matematicamente e ser capaz de } \\
\text { trabalhar na busca de soluções e na resolução de } \\
\text { problemas. (DENISE, P19, 23/11/10) }\end{array}$ \\
\hline
\end{tabular}

Fonte: elaborado pelas autoras.

Os critérios que eu usava antes eram de verificação. Eu continuo escolhendo tarefas para verificar, só que surgiram outras razões. Agora escolbo tarefas de alto nivel, tarefas que explorem o raciocínio, e ajudem o aluno a desenvolver-se intelectualmente. [...] Eu acredito que todos os tipos de tarefas são importantes. (ANA LÍVIA, E, 30/11/10)

Aquelas razões que eu tinha ficaram, e junto com elas agora eu escolbo tarefas que sejam de alto nivel, exercicios de raciocinio, e não só aquelas que envolvem só fórmulas. Eu procuro um equilibrio nas tarefas. (FERNANDA, E, 30/11/10)

Segundo Stein et al. (2009), as tarefas que envolvem elevado nível de demanda cognitiva fornecem oportunidades para que os alunos desenvolvam a capacidade de pensar matematicamente e a autonomia.

\section{Quanto ao trabalho com os alunos}

Colocar-se no lugar do aluno, ao resolver e discutir as tarefas, permitiu que as professoras percebessem que cada um tem seu ritmo e suas dificuldades.

As reflexões explicitadas após a proposição e implementação de tarefas de elevado nível de demanda cognitiva em sala de aula, indicam que elas passaram a reconhecer que:

- estudantes considerados "bons" em tarefas menos complexas não foram tão bemsucedidos no trabalho com tarefas de elevado nível de demanda cognitiva;

- não devemos subestimar a capacidade de nossos alunos, pois aqueles que elas acreditavam que não teriam potencial para resolver a tarefa, fizeram-na sem maiores dificuldades;

- o modo como o aluno resolve a tarefa é tão ou mais importante que o resultado final;

- o professor precisa estar preparado para propor tarefas de elevado nível de demanda cognitiva;

- é preciso questionar os alunos a respeito de suas resoluções, estando corretas ou não;

- não é interessante propor somente tarefas com foco na memorização ou na realização de um procedimento sem significado.

Eu escolbia [só] tarefas para verificação. Hoje eu procuro tarefas que levam o aluno a pensar, não apenas aquelas tarefas que só focam na resposta, mas em como o aluno 
vai faz̧er, no processo. Mas, eu continuo também escolhendo tarefas para verificação, porque acho que são importantes também. Não dá ainda para descartá-las, eu preciso ter segurança para trabalhar com tarefas de elevado nivel e os alunos também. A minha postura dentro de sala de aula também mudou, procuro agora questionar mais os alunos para saber como ele pensou. Eu acho que os outros critérios surgiram devido a minha participação no grupo, porque eu não teria este conbecimento, essa visão sem ter participado. (ANA JÚLIA, E, 30/11/10)

De acordo com Stein et al. (2009), é imprescindível, ao professor, o monitoramento de si e de suas reflexões a respeito do seu processo de ensino, pois "cultivar hábitos de reflexão ponderada e sistemática pode ser a chave tanto para melhorar o ensino como para sustentar o seu desenvolvimento profissional ao longo da vida” (STEIN; SMITH, 1998, p. 268, tradução nossa).

\section{Quanto ao enfrentamento de crenças que permeiam a prática pedagógica}

No decorrer das discussões do grupo de estudo, percebemos, nas declarações das professoras, algumas crenças quanto à prática pedagógica, tais como: "a tarefa tem que ser prazerosa para garantir a aprendizagem", "as tarefas que estão relacionadas com a realidade do aluno são prazerosas", "trabalhar com tarefas que envolvem outros aspectos, além da matemática, garantem a interdisciplinaridade", "épreciso interpretar pelo aluno", entre outras.

Discutimos que o aluno pode "ter prazer" ao realizar tarefas sem que essas estejam necessariamente relacionadas com sua realidade. Tarefas relacionadas à realidade do aluno nem sempre são prazerosas ou envolventes. A "vontade de aprender" é do sujeito, é interna, vem "de dentro para fora". Um aluno pode se sentir desafiado por uma tarefa, enquanto outro aluno não. Consideramos importante que o professor conheça seus alunos e investigue o tipo de tarefas nas quais eles se disponham a conjecturar, argumentar, estabelecer relações e desenvolver estratégias de resolução.

As reflexões promovidas no grupo permitiram às docentes compreender o impacto que suas ações têm nos processos de ensino e de aprendizagem, e propiciar mudanças em relação ao seu modo de escolher e propor tarefas em sala de aula. Elas demonstraram uma preocupação com a compreensão dos alunos que antes não era considerada.

\section{Considerações finais}

Sabemos que a tarefa matemática por si só não é suficiente para gerar uma atividade matemática significativa, e não temos a visão ingênua de que, para transformar o ensino, basta propor boas tarefas. No entanto, reconhecemos a necessidade de o professor refletir a respeito delas para que possa fazer escolhas e proposições que sejam adequadas à aprendizagem dos alunos.

A formação continuada desenvolvida com as professoras não seguiu os pressupostos de um curso tradicional, no qual são ensinados conteúdos matemáticos ou estratégias metodológicas. Constituímos um espaço para que elas pudessem estudar, partilhar experiências e repertórios, discutir e refletir a respeito de sua prática pedagógica, tendo como mote a análise de tarefas matemáticas. 
O compromisso/engajamento mútuo em torno de um empreendimento articulado e um repertório compartilhado foram elementos centrais da prática dessas professoras no processo de formação continuada, e revelaram aspectos do seu desenvolvimento profissional. As professoras assumiram o papel de protagonistas do processo de construção de seus conhecimentos profissionais, pois passaram a:

- avaliar quais tarefas oferecem oportunidades para o aluno desenvolver uma matemática com significado, e para que as características superficiais das tarefas não interfiram no momento de escolhê-las;

- selecionar ou elaborar tarefas que estão em consonância com seus objetivos de ensino, a fim de que a escolha de tarefas seja uma ação pensada, uma vez que as tarefas encaminham à aprendizagem do aluno;

- perceber que o nível de pensamento no qual o aluno trabalha pode determinar o que ele irá aprender;

- organizar um processo de ensino em que o "caminho" escolhido pelo aluno para a resolução de uma tarefa seja mais valorizado do que a resposta correta;

- perceber que as oportunidades de aprendizagem não estão, simplesmente, relacionadas com o fato de colocar os alunos em grupos, ou diante de materiais manipulativos, ou recursos computacionais, mas com as reflexões que são promovidas por meio das tarefas;

- reconhecer que diferentes tarefas podem constituir diferentes oportunidades para o aluno pensar, a fim de que não ocorra o privilégio de um único tipo de tarefa na sua prática pedagógica, de modo a não limitar os processos de ensino e de aprendizagem.

A dinâmica assumida pelo grupo respeitou e legitimou a individualidade, as emoções (frustração, medo, desejo de acertar, insegurança), as experiências, os conhecimentos, constituindo um ambiente de confiança e respeito mútuo. Podemos dizer que essa dinâmica permitiu a constituição de uma comunidade de prática (CYRINO; CALDEIRA, 2011; WENGER, 1998).

As professoras foram desafiadas a sair da "zona de conforto" e analisar criticamente as suas práticas. Não temos como avaliar se os conhecimentos produzidos por elas foram incorporados em sala de aula, ou quanto tempo vai demorar para que isso ocorra. Sabemos que os hábitos, as crenças e as pressões (institucionais e particulares) impostas a elas são muito fortes, no entanto acreditamos que elas vivenciaram uma oportunidade viável de formação, com vistas ao desenvolvimento profissional de professores que ensinam matemática.

\section{Agradecimentos}

As autoras agradecem a Fundação Araucária pelo apoio financeiro, ao Conselho Nacional de Desenvolvimento Científico e Tecnológico (CNPq) pela bolsa de produtividade em pesquisa (M.C.C.T.C.) e a Coordenação de Aperfeiçoamento de Pessoal de Nível Superior (CAPES) pela bolsa de mestrado (C.C.J.).

\section{Referências}

ARBAUGH, F.; BROWN, C. A. Analyzing mathematical tasks: a catalyst for change? Journal of Mathematics Teacher Education, Dordrecht, v. 8, n. 6, p. 499-536, 2005.

BARDIN, L. Análise de conteúdo. Lisboa: Edições 70, 1977. 
BISPO, R.; RAMALHO, G.; HENRIQUES, N. Tarefas matemáticas e desenvolvimento do conhecimento matemático no $5^{\circ}$ ano de escolaridade. Análise Psicológica, Lisboa, v. 1, n. 26, p. 3-14, 2008.

BRÄNDSTRÖM, A. Differentiated tasks in mathematics textbooks: an analysis of the levels of difficulty. 2005. 117 f. Tese (Licentiate Thesis) - Department of Mathematics, Lulea University of Technology, Lulea, 2005.

CHRISTIANSEN, B.; WHALTER, G. Task and activity. In: CHRISTIANSEN, B.; HOWSON, A. G.; OTTE, M. (Ed.). Perspective on mathematics education. Dordrecht: Reidel, 1986. p. 243-307.

CYRINO, M. C. C. T.; CALDEIRA, J. S. Processos de negociação de significados sobre pensamento algébrico em uma comunidade de prática de formação inicial de professores de Matemática.

Investigações em Ensino de Ciências, Porto Alegre, v. 16, n. 3, p. 373-401, 2011.

DOYLE, W. Academic work. Review of Educational Research, Thousand Oaks, v. 53, n. 2, p. 159-199, 1983.

LÜDKE, M.; ANDRÉ, M. E. D. A. Pesquisa em educação: abordagens qualitativas. São Paulo: EPU, 1986.

NATIONAL COUNCIL OF TEACHERS OF MATHEMATICS (NCTM). Principles and standards for school mathematics. Reston: Authors, 2000.

PHILLIPS, E.; CRESPO, S. Developing written communication in Mathematics through math penpal letters. For the Learning of Mathematics, Kingston v. 16, n. 1, p. 15-22, 1996.

PORTUGAL. Associação de Professores de Matemática. Tarefas e atividades como elementos do currículo de matemática. In: O PROFESSOR e o desenvolvimento curricular. Lisboa: APM, 2005. p. 39-72.

SHIMIZU, Y. et al. The role of mathematical tasks in different cultures. In: SHIMIZU, Y. et al. (Org.). Mathematical tasks in classrooms around the world. Boston: Sense Publishers, 2010. p. 1-14.

SIMON, M. A.; TZUR, R. Explicating the role of mathematical tasks in conceptual learning: an elaboration of the hypothetical learning trajectory. Mathematical Thinking and Learning, Philadelphia , v. 6, n. 2, p. 91-104, 2004.

STEELE, D. F. Vozes entusiastas de jovens matemáticos. Educação e Matemática, Lisboa, v. 62, p. 39-42, 2001.

STEIN, M. K. et al. Implementing standards-based mathematics instruction: a casebook for professional development. New York: Teachers College Press, 2009.

STEIN, M. K.; GROVER, B. W.; HENNINGSEN, M. Building student capacity for mathematical thinking and reasoning: an analysis of mathematical tasks used in reform classrooms. America Educational Research Journal, Washington, v. 33, n. 2, p. 455-488, 1996.

STEIN, M. K.; SMITH, M. S. Mathematical tasks as a framework for reflection: from research to practice. Mathematics Teaching in the Middle School, Reston, v. 3, n. 4, p. 268-275, 1998.

WATSON, A.; SULLIVAN, P. Teachers learning about tasks and lessons. In: TIROSH, D. (Ed.). Tools and processes in mathematics teacher education. London: Sense Publishers, 2008. p.109-134.

WENGER, E. Communities of practice: learning, meaning and identity. New York: Cambridge University Press, 1998.

Artigo recebido em 16/10/12. Aceito em 21/06/13. 